Case Report

\title{
Two-Step Laparoscopic Surgery for a Patient with Synchronous Double Cancer of the Colon and Stomach Accompanied by Severe Chronic Obstructive Pulmonary Disease
}

\author{
Kazuhito Yajima, Shin-Ichi Kosugi, Yosuke Kano, Takaaki Hanyu, Hiroshi Ichikawa, \\ Takashi Ishikawa, Hitoshi Nogami, and Toshifumi Wakai
}

Division of Digestive and General Surgery, Niigata University Graduate School of Medical and Dental Sciences, 1-757 Asahimachi-Dori, Niigata 951-8510, Japan

Correspondence should be addressed to Kazuhito Yajima; yajikazu@nifty.com

Received 29 May 2013; Accepted 5 August 2013

Academic Editors: D. J. Bentrem, D. Mantas, M. Picchio, G. Rallis, J. M. Strzelczyk, and B. Tokar

Copyright (C) 2013 Kazuhito Yajima et al. This is an open access article distributed under the Creative Commons Attribution License, which permits unrestricted use, distribution, and reproduction in any medium, provided the original work is properly cited.

\begin{abstract}
Laparoscopic treatment strategies for synchronous intra-abdominal malignancies have not yet been standardized. We report a successful case of two-step laparoscopic surgery for synchronous double cancer of the colon and stomach accompanied by severe chronic obstructive pulmonary disease (COPD). A 66-year-old man with COPD was diagnosed as having advanced colon cancer and early gastric cancer. On admission, he could not go upstairs (Grade III according to the Hugh-Jones classification) and his forced expiratory volume in 1 second was $600 \mathrm{~mL}$ (35.9\%). The patient initially underwent laparoscopy-assisted sigmoidectomy with D3 lymphadenectomy, followed by laparoscopy-assisted distal gastrectomy with D1 lymphadenectomy 68 days later. The patient's each postoperative course was uneventful with no pulmonary complications, and the patient was discharged 9 and 11 days after the first and second operations, respectively. The present case demonstrates that two-step laparoscopic surgery may be a safe and feasible surgical procedure for high-risk patients with synchronous intra-abdominal malignancies.
\end{abstract}

\section{Introduction}

Laparoscopic surgery is recognized as a general surgical procedure for intra-abdominal malignancies $[1,2]$. Recent publications have been reported on laparoscopy-assisted combined resection in patients with synchronous gastric and colorectal cancer [3-8]. However, laparoscopic treatment strategies for synchronous intra-abdominal malignancies have not yet been standardized, especially in patients with severe pulmonary comorbidity. Herein, we report on a twostep laparoscopic surgery in a patient with synchronous double cancer of the colon and stomach accompanied by severe chronic obstructive pulmonary disease (COPD).

\section{Case Report}

A 66-year-old man presented to the local hospital with a chief complaint of frequent loose stools and difficulty in defecation. He had smoked 40 cigarettes per day for 35 years, with his
Brinkman index of 1400 , and he has been having a history of COPD since 1999. Colonoscopy revealed a circumferential tumor in the sigmoid colon, with pathological examination indicating well-differentiated adenocarcinoma. The clinical diagnosis was advanced sigmoid colon cancer without nodal metastasis on enhanced abdominal-pelvic computed tomography. Screening the upper gastrointestinal endoscopy revealed a superficial depressed tumor in the greater curvature of the lower third of the stomach with pathological examination indicating well-differentiated adenocarcinoma. Submucosal invasion was clinically determined on endoscopy and upper gastrointestinal series; accordingly, surgical resection was recommended for both the sigmoid colon cancer and gastric cancer. On admission, the patient could not go upstairs (Grade III according to the Hugh-Jones classification) and breathed through pursed lips at rest. His vital capacity was $2530 \mathrm{~mL}$ (73.3\%) and his forced expiratory volume in 1 second $\left(\mathrm{FEV}_{1.0}\right)$ was $580 \mathrm{~mL}$ (35.9\%). Chest radiography revealed increased lung transparency and cor 
pulmonale. These findings Compatible with COPD. Arterial blood gas analysis on admission revealed $\mathrm{pH}$ 7.397, $\mathrm{PO}_{2}=$ $79.3 \mathrm{mmHg}$, and $\mathrm{PCO}_{2}=43.2 \mathrm{mmHg}$.

Because of the diagnosis of advanced colon cancer and early gastric cancer, we decided to perform a two-step laparoscopic surgery to shorten the operation time and to avoid postoperative pulmonary complications. After admission, the patient underwent respiratory rehabilitation consisting of 3 weeks training using a TRIFLO II (Philips Respironics CK, Tokyo, Japan) and inhalation therapy. In September 2009, the patient underwent laparoscopy-assisted sigmoidectomy with D3 lymphadenectomy using four ports and the pneumoperitone method with an intra-abdominal pressure of $8 \mathrm{mmHg}$. Lymphadenectomy was performed using the medial-to-lateral approach [9] with resection margins of $10 \mathrm{~cm}$ on both the oral and anal sides of the tumor. The resected specimen was removed from a $5 \mathrm{~cm}$ incision in the lower abdomen (Figure 1). The colorectal anastomosis was laparoscopically performed by the double-stapling technique using circular stapler (DST Series EEA Stapler 28; Covidien Japan, Tokyo, Japan). The operation time was $177 \mathrm{~min}$ and the volume of blood lost was $5 \mathrm{~mL}$.

Sixty-eight days after the initial surgery for colon cancer, the patient underwent laparoscopy-assisted distal gastrectomy (LADG) using four ports and the pneumoperitoneal method with an intra-abdominal pressure of $8 \mathrm{mmHg}$. The first trocar was inserted into the abdominal cavity from the right lower quadrant by open method. There was minimal adhesion of the omentum at the umbilical port site (Figure 2(a)). D1 lymphadenectomy was performed by an usual method (Figure 2(b)), and transection of the duodenum and stomach was cut using an endoscopic liner stapler (GIA stapling system, blue; Covidien, Tokyo, Japan, Figure 2(c)). Billroth I reconstruction was performed by the hemi-double-stapling technique using circular stapler (DST Series EEA Stapler 28; Covidien Japan, Figure 2(d)) [10]. Removal of the resected stomach and anastomosis were performed through a $4 \mathrm{~cm}$ incision in the upper middle abdomen (Figure 1). The operation time was $136 \mathrm{~min}$ and the estimated blood loss was $35 \mathrm{~mL}$. Intra-abdominal adhesion was minimal and, more importantly, gastrectomy could be performed safely and easily even though it was the second major surgery.

For both surgeries, the patient was under general anesthesia induced by propofol (1\% Diprivan Injection; AstraZeneca, Osaka, Japan), vecuronium bromide (Musculax Intravenous; Schering-Plough, Osaka, Japan), and epidural anesthesia using ropivacaine hydrochloride hydrate (Anapeine Injection; AstraZeneca). The patient was extubated immediately in the operating theatre after recovering from anesthesia. The patient was managed postoperatively in the intensive care unit until postoperative day (POD) 1. The patient's each postoperative course was uneventful and he was discharged on POD 9 and 11 after the first and second operations, respectively. The patient is alive with no evidence of recurrence of either tumor 24 months after the initial colonic surgery and has a good quality of life without impairment of pulmonary dysfunction.

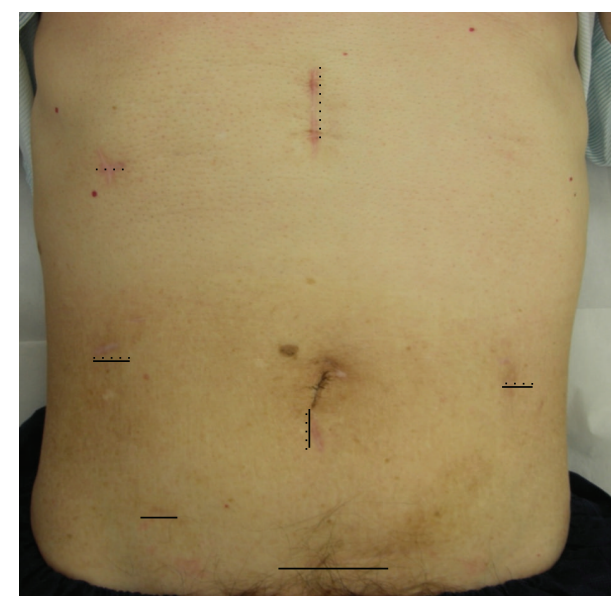

FIgURE 1: Port sites and minilaparotomy incision after sigmoidectomy and gastrectomy. Laparoscopic-assisted sigmoidectomy was performed via four ports and a $5 \mathrm{~cm}$ mini-laparotomy of the lower abdomen (solid lines). Laparoscopy-assisted distal gastrectomy was performed via four ports and a $4 \mathrm{~cm}$ mini-laparotomy of the upper abdomen (dotted lines).

The resected sigmoid colon contained a nearly circumferential polypoid tumor, $58 \times 38 \mathrm{~mm}$ in size (Figure $3(\mathrm{a})$ ). Histological examination revealed well-differentiated adenocarcinoma invading the subserosa (Figure 3(b)), with no lymph node metastasis, which was pathologically classified as Stage II [11]. The resected stomach contained a superficial depressed and elevated type tumor, $25 \times 20 \mathrm{~mm}$ in size (Figure 3(c), black arrow head). Histological examination revealed well-differentiated to moderately differentiated adenocarcinoma to the depth of the mucosa (Figure 3(d)), with no lymph node metastasis, which was pathologically classified as Stage IA [12].

\section{Discussion}

This is the first report of two-step laparoscopic resection for a patient synchronous double cancer of the colon and stomach accompanied by severe pulmonary comorbidity. Although the patient's respiratory function was very poor, the postoperative course after both operations was uneventful, with no pulmonary complications. The present case demonstrates that the two-step laparoscopic surgery may be a safe and feasible surgical technique for high-risk patients with synchronous intra-abdominal malignancies.

Laparoscopic gastrectomy is the accepted procedure for the treatment of early gastric cancer because of its superiority to conventional open gastrectomy in terms of less postoperative pain, less blood loss, and earlier postoperative recovery [13]. Currently, across all the centers registered in Japan to perform endoscopic surgery, $27.9 \%$ of operations for gastric cancer are performed laparoscopically [14]. For colon cancer, laparoscopic surgery is even more common, with a nationwide survey in Japan reporting that $46.8 \%$ of colorectal surgeries are performed laparoscopically [14]. In our division, we have performed laparoscopic gastrectomy in patients with 


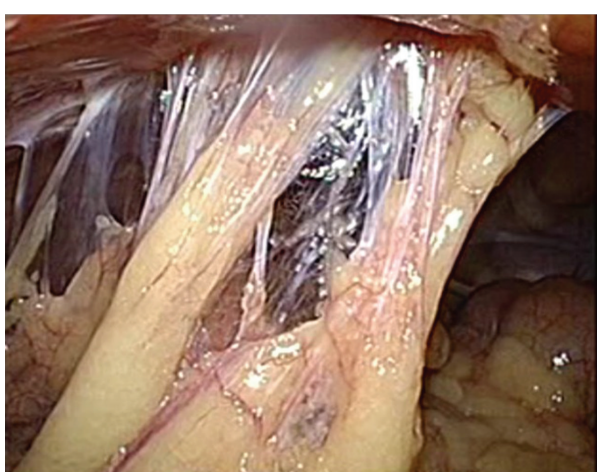

(a)

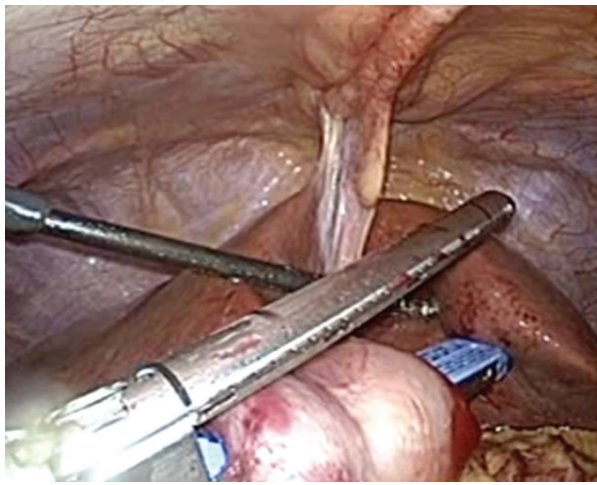

(c)

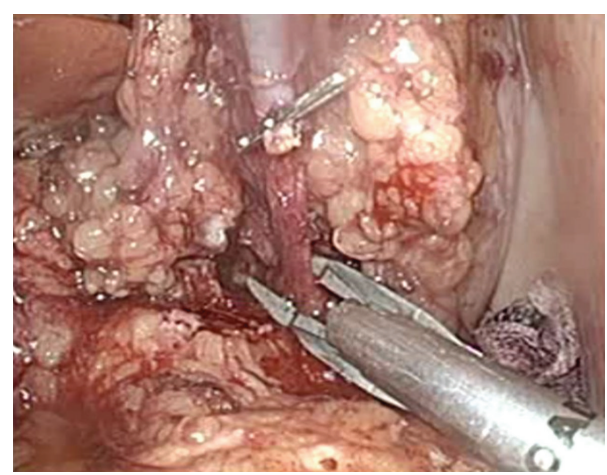

(b)

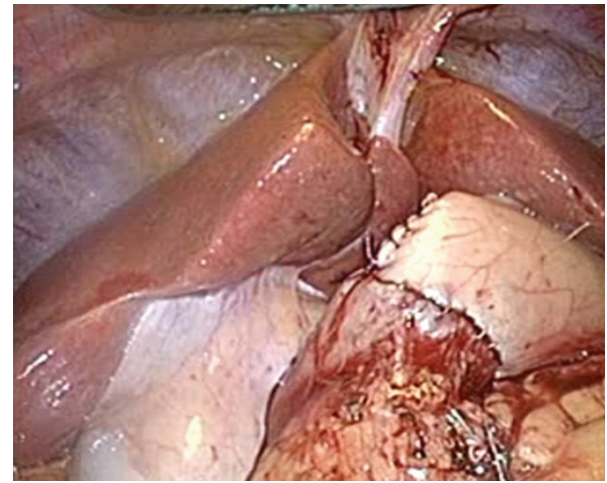

(d)

Figure 2: Intra-abdominal findings during laparoscopy-assisted distal gastrectomy with lymphadenectomy. (a) There was minimal adhesion of the omentum at the umbilical port site. (b) Dissection of lymph node stations 7 (lymph nodes along the trunk of left gastric artery). (c) Transection of the duodenum: the duodenum was cut nearly distal to the pylorus using an endoscopic liner stapler (GIA stapling system, blue; Covidien, Tokyo, Japan). (d) Billroth I reconstruction was performed by a hemi-double-stapling technique using circular stapler (DST Series EEA Stapler 28; Covidien Japan).

clinical T1 gastric cancer with no lymph node metastasis since July 2002, and laparoscopic colectomy has been performed in patients with colorectal cancer with no clinical evidence of invasion to adjacent organs since August 1995.

The treatment for patients with synchronous colon and gastric cancer has been one-step resection. Although the precise surgical procedure depends on the location of both the gastric and colorectal cancers, the biggest disadvantage associated with conventional one-step open surgery is the extensive surgical manipulation. To reduce the invasiveness of the resection, laparoscopic simultaneous resections were recently introduced for patients with these double cancers. To characterize laparoscopic simultaneous resections and to determine any problems associated with the procedure, we searched the PubMed database using the keywords "laparoscopy," "gastric cancer," and "colorectal cancer." As of December 2012, there were six reports on 16 patients, including reference lists, describing laparoscopic surgery for synchronous gastric and colorectal cancer [3-8]. All 16 cases and our case are summarized in Table 1.

As indicated in Table 1, LADG was selected for 11 patients with gastric cancer, laparoscopy-assisted total gastrectomy was performed in two patients, laparoscopy-assisted pyloruspreserving gastrectomy was performed in another two patients, and laparoscopy-assisted proximal gastrectomy was performed in one patient. Various procedures were performed for colonic resection, which included right colectomy in six patients, sigmoidectomy in four patients, low anterior resection in another four patients, and partial resection, left colectomy, and ileocecal resection in one patient each. The median operation time was $386 \mathrm{~min}$ (range, 263-746 min), and median blood loss was $147.5 \mathrm{~mL}$ (range, $15-500 \mathrm{~mL}$ ). The median postoperative hospital stay was 14 days (range, 6-51 days). There were four postoperative complications including wound infection, surgical site infection, enteritis, and gastric fullness in one patient each. On the basis of these outcomes, it appears that the less-invasive laparoscopic surgery is useful in the case of both colon and gastric cancers and is associated with good short-term outcome.

Although the laparoscopic approach is a feasible procedure for synchronous gastric and colorectal cancer, there are two major limitations. First, the simultaneous laparoscopic procedure is time consuming: it took longer than $5 \mathrm{~h}$ to be completed in $14(87.5 \%)$ of the 16 patients, with $>12 \mathrm{~h}$ (746 min) required in one patient (Table 1). Second, there seem to be difficulties in determining port sites and small skin incisions for the resection and anastomosis. Tokunaga et al. [6] reported that the minilaparotomy and port sites depend on the location of both the gastric and colonic tumors, with seven patients undergoing simultaneous laparoscopic surgery 


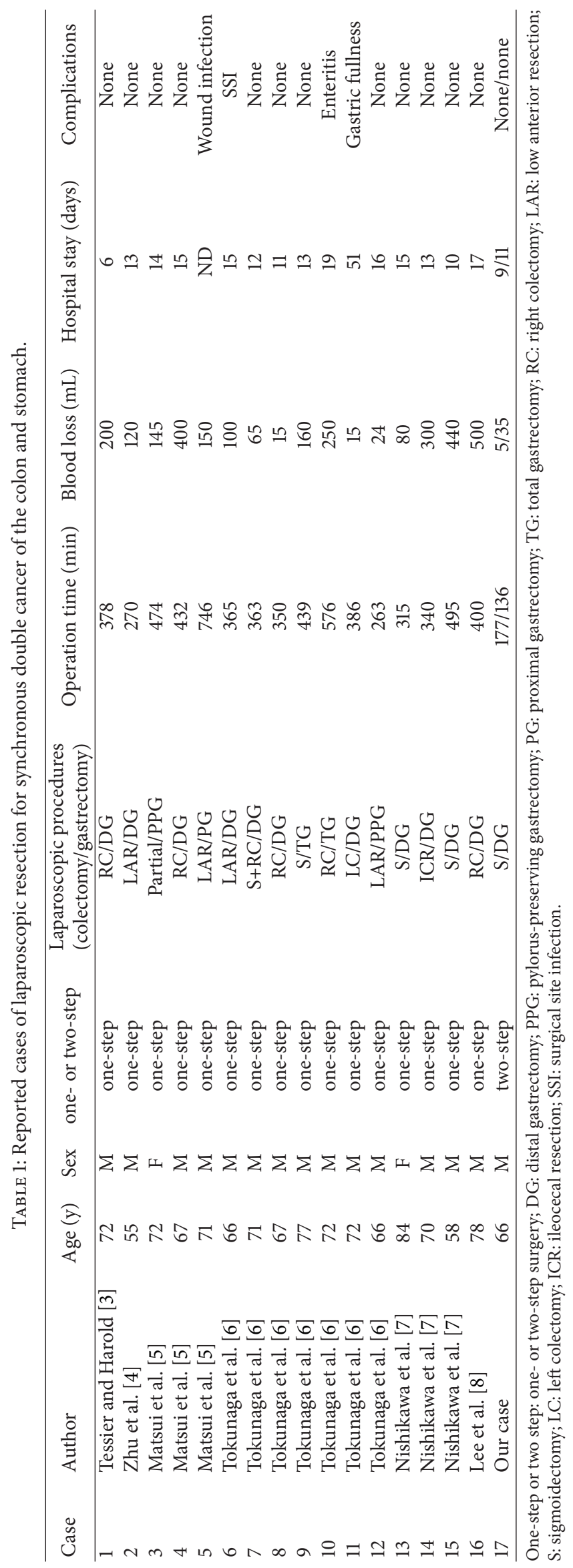




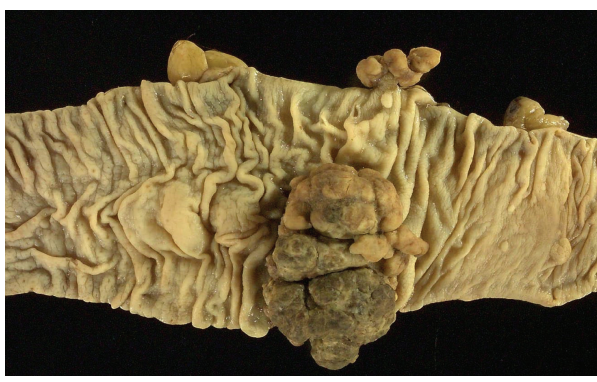

(a)

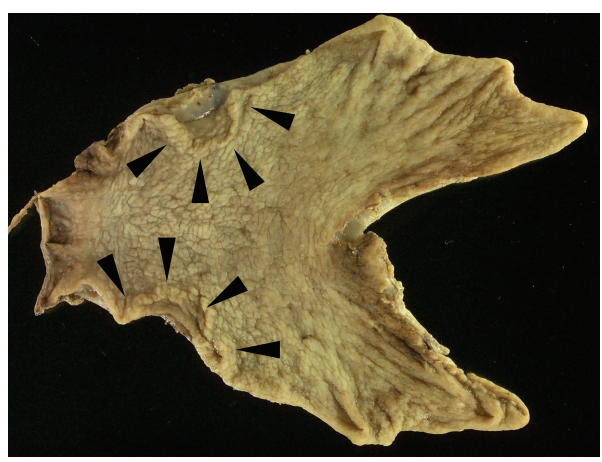

(c)

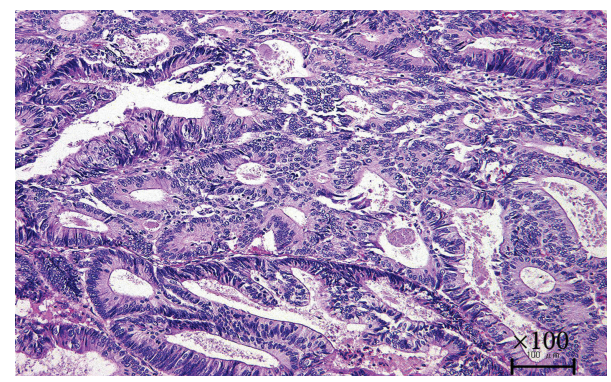

(b)

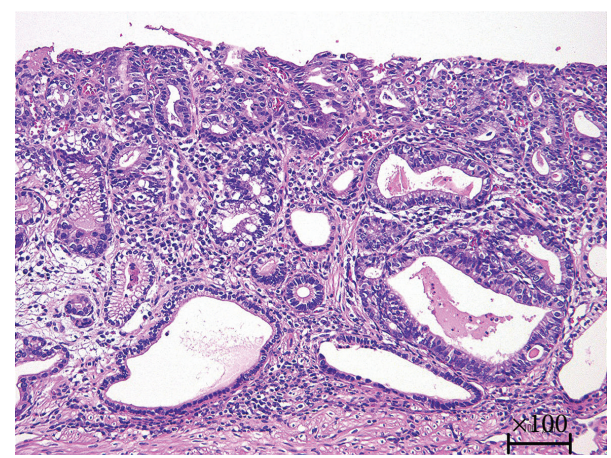

(d)

Figure 3: Macroscopic and microscopic findings of the sigmoid colon and gastric cancers. (a) The sigmoid colon contained a nearly circumferential polypoid tumor. (b) Histological examination revealed well-differentiated adenocarcinoma invading the subserosa (hematoxylin and eosin; original magnification, $\times 100$ ). (c) The stomach contained a superficial depressed and elevated type tumor in the greater curvature of the lower third of the stomach (black arrowheads). (d) Histological examination revealed well- to moderately differentiated adenocarcinoma confined to the mucosa (hematoxylin and eosin; original magnification, $\times 100$ ).

in their report requiring three minilaparotomy wounds. Matsui et al. [5] reported that the combined resection of the right-side colon and stomach was relatively easy and was performed sharing the same minilaparotomy and ports. In the present case, if the operation had been performed simultaneously, totally laparoscopic distal gastrectomy and sigmoidectomy with minilaparotomy extending umbilical port site may have been needed because the colon cancer was located in the sigmoid colon.

Laparoscopic simultaneous resection of gastric and colorectal cancer in patients with comorbidities, especially severe pulmonary complications, has not been reported. Carbon dioxide $\left(\mathrm{CO}_{2}\right)$ is generally used in laparoscopic surgery to create a pneumoperitoneum because it is quickly absorbed from the peritoneal cavity into the circulation; however, there is little known about its effect on patients with severe COPD. In general, pulmonary function is impaired following major abdominal surgery because of limited functioning of the diaphragm. In a retrospective study, Chang et al. [15] reported on 61 patients with COPD undergoing laparoscopic gastrectomy. They found significant changes in end-tidal $\mathrm{CO}_{2}$ and $\mathrm{P}_{\mathrm{a}} \mathrm{CO}_{2}$ during laparoscopic gastrectomy, but the procedure could be performed safely in patients with mild to moderate COPD. Because our patient had very severe COPD according to the Chang's criteria [15], with FEV 1.0 ratio of $23 \%$, we intended to perform the two-step laparoscopic surgery for synchronous double cancer of colon and stomach. We were able to safely complete laparoscopyassisted colectomy at first the operation, followed by LADG at the second operation with no postoperative pulmonary complications.

\section{Conclusions}

In conclusion, herein we report on successful two-step laparoscopy resection for a patient with synchronous double cancer of the colon and stomach accompanied by severe pulmonary comorbidity. Two-step laparoscopic surgery is useful because it reduces the operative time and minimizes the length of the surgical incision. This strategy may be safe and feasible for high-risk patients with synchronous intraabdominal malignancies.

\section{Conflict of Interests}

The authors declare there is no conflict of interests.

\section{References}

[1] S. Kitano, N. Shiraishi, I. Uyama et al., "A multicenter study on oncologic outcome of laparoscopic gastrectomy for early cancer in Japan," Annals of Surgery, vol. 245, no. 1, pp. 68-72, 2007.

[2] W. L. Law, Y. M. Lee, H. K. Choi, C. L. Seto, and J. W. C. Ho, "Impact of laparoscopic resection for colorectal cancer on 
operative outcomes and survival," Annals of Surgery, vol. 245, no. 1, pp. 1-7, 2007.

[3] D. J. Tessier and K. L. Harold, "Combined laparoscopic near-total gastrectomy and colectomy," Surgical Laparoscopy, Endoscopy and Percutaneous Techniques, vol. 15, no. 5, pp. 290293, 2005.

[4] Q.-L. Zhu, M.-H. Zheng, B. Feng et al., "Simultaneous laparoscopy-assisted low anterior resection and distal gastrectomy for synchronous carcinoma of rectum and stomach," World Journal of Gastroenterology, vol. 14, no. 21, pp. 3435-3437, 2008.

[5] H. Matsui, Y. Okamoto, A. Ishii et al., "Laparoscopy-assisted combined resection for synchronous gastric and colorectal cancer: report of three cases," Surgery Today, vol. 39, no. 5, pp. 434-439, 2009.

[6] M. Tokunaga, N. Hiki, T. Fukunaga et al., "Laparoscopic surgery for synchronous gastric and colorectal cancer: a preliminary experience," Langenbeck's Archives of Surgery, vol. 395, no. 3, pp. 207-210, 2010.

[7] M. Nishikawa, M. Higashino, S. Tanimura, Y. Fukunaga, and T. Tokuhara, "Three cases of synchronous laparoscopic resection for gastric and colonic cancer," Surgical Laparoscopy, Endoscopy and Percutaneous Techniques, vol. 20, no. 6, pp. e218-e225, 2010.

[8] J. Lee, Y. Nam, and W. Kim, "Simultaneous laparoscopy-assisted distal gastrectomy and right hemicolectomy for synchronous advanced gastric and colon cancer," Surgical Laparoscopy, Endoscopy and Percutaneous Techniques, vol. 20, no. 4, pp. 257261, 2010.

[9] J.-T. Liang, M.-J. Shieh, C.-N. Chen, Y.-M. Cheng, K.-J. Chang, and S.-M. Wang, "Prospective evaluation of laparoscopyassisted colectomy versus laparotomy with resection for management of complex polyps of the sigmoid colon," World Journal of Surgery, vol. 26, no. 3, pp. 377-383, 2002.

[10] H. Fujii, T. Aotake, Y. Kawakami et al., "Modified hemi-doublestapling technique combined with the temporal abdominal wall-lift method for performing Billroth I anastomosis after laparoscopically assisted distal gastrectomy," Surgical Endoscopy and Other Interventional Techniques, vol. 22, no. 12, pp. 27482752, 2008.

[11] Japanese Society for Cancer of the Colon and Rectum, Japanese Classification of Colorectal Carcinoma, Kanehara, Tokyo, Japan, 2nd edition, 2009.

[12] Japanese Gastric Cancer Association, "Japanese classification of gastric carcinoma: 3rd English edition," Gastric Cancer, vol. 14, no. 2, pp. 101-112, 2011.

[13] C. G. S. Huscher, A. Mingoli, G. Sgarzini et al., "Laparoscopic versus open subtotal gastrectomy for distal gastric cancer: five-year results of a randomized prospective trial," Annals of Surgery, vol. 241, no. 2, pp. 232-237, 2005.

[14] "11th nationwide survey of endoscopic surgery in Japan," Journal of Japan Society for Endoscopic Surgery, vol. 17, pp. 567-694, 2012.

[15] H.-M. Chang, S.-W. Lee, E. Nomura, and N. Tanigawa, "Laparoscopic versus open gastrectomy for gastric cancer patients with COPD," Journal of Surgical Oncology, vol. 100, no. 6, pp. 456458, 2009. 


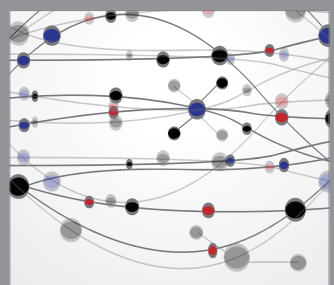

The Scientific World Journal
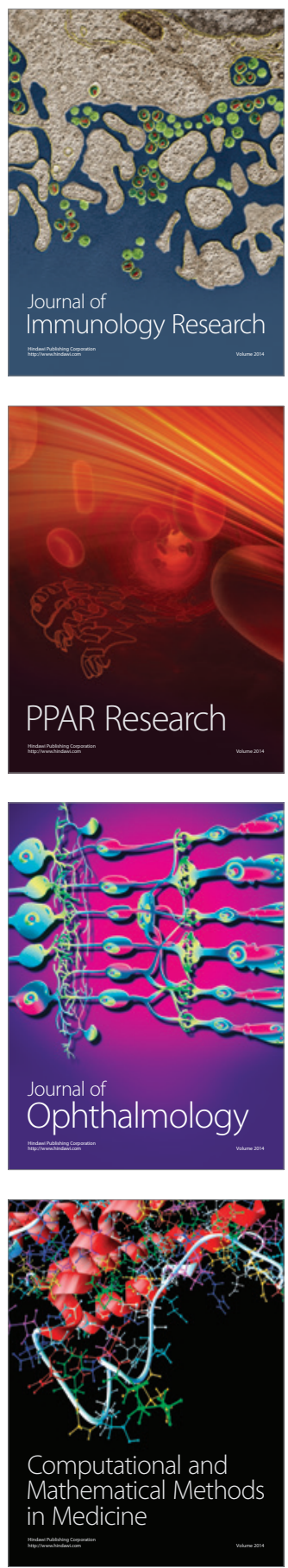

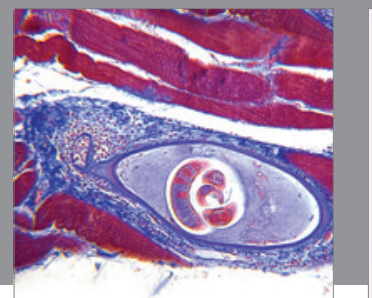

Gastroenterology

Research and Practice
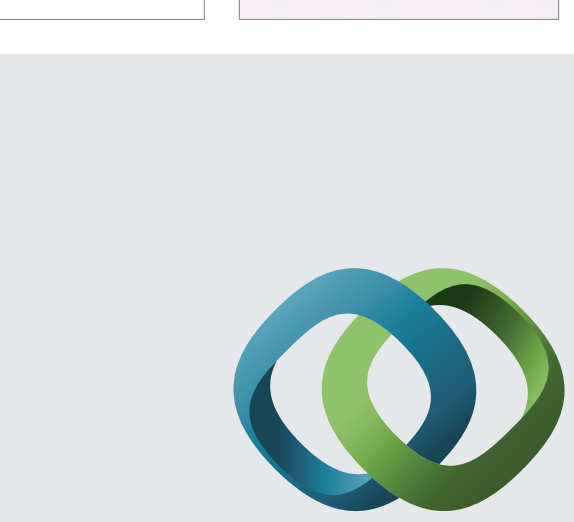

\section{Hindawi}

Submit your manuscripts at

http://www.hindawi.com
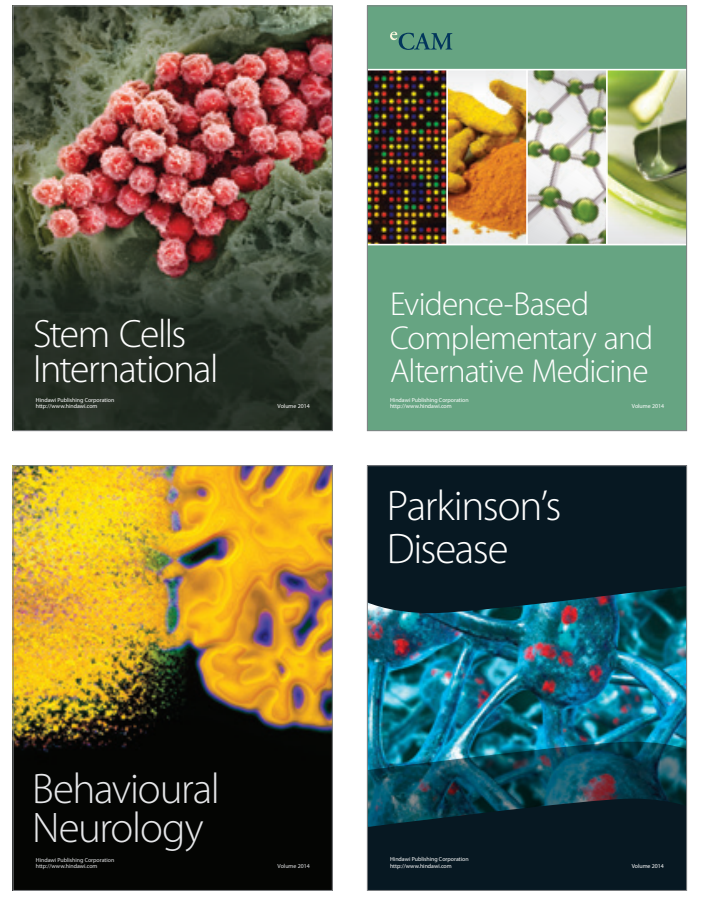
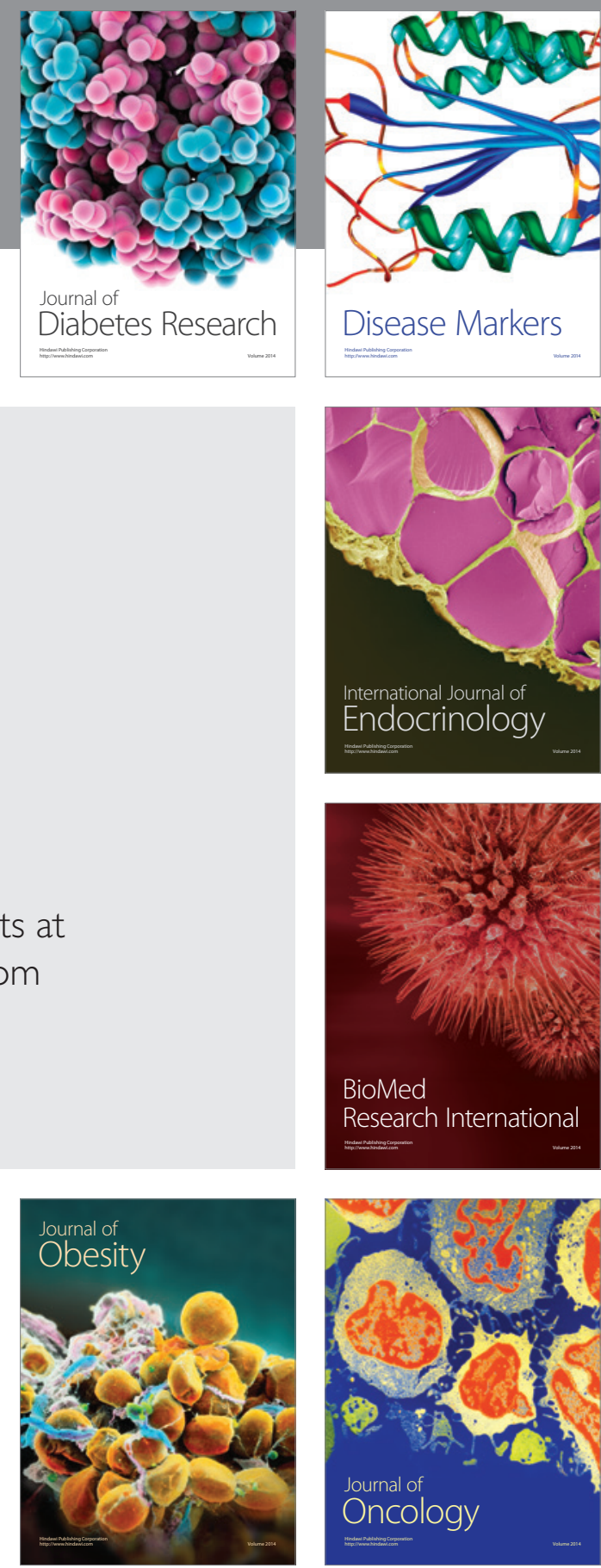

Disease Markers
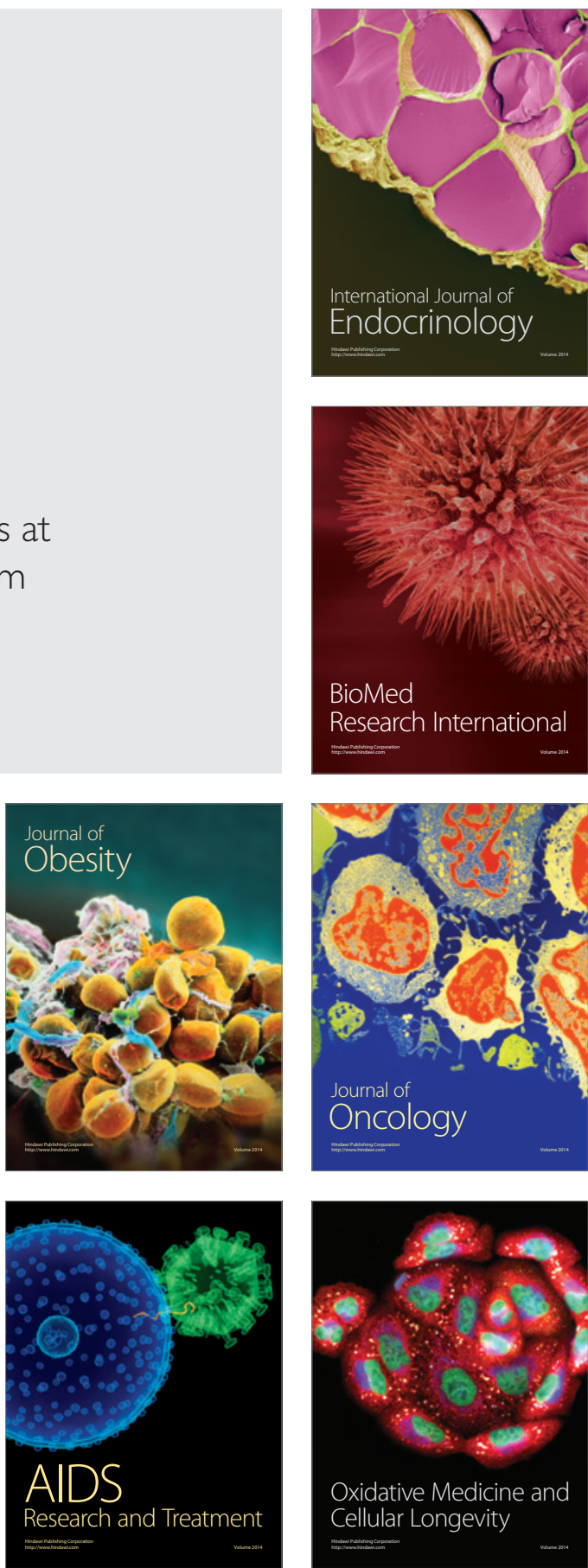